BMC

Research Notes

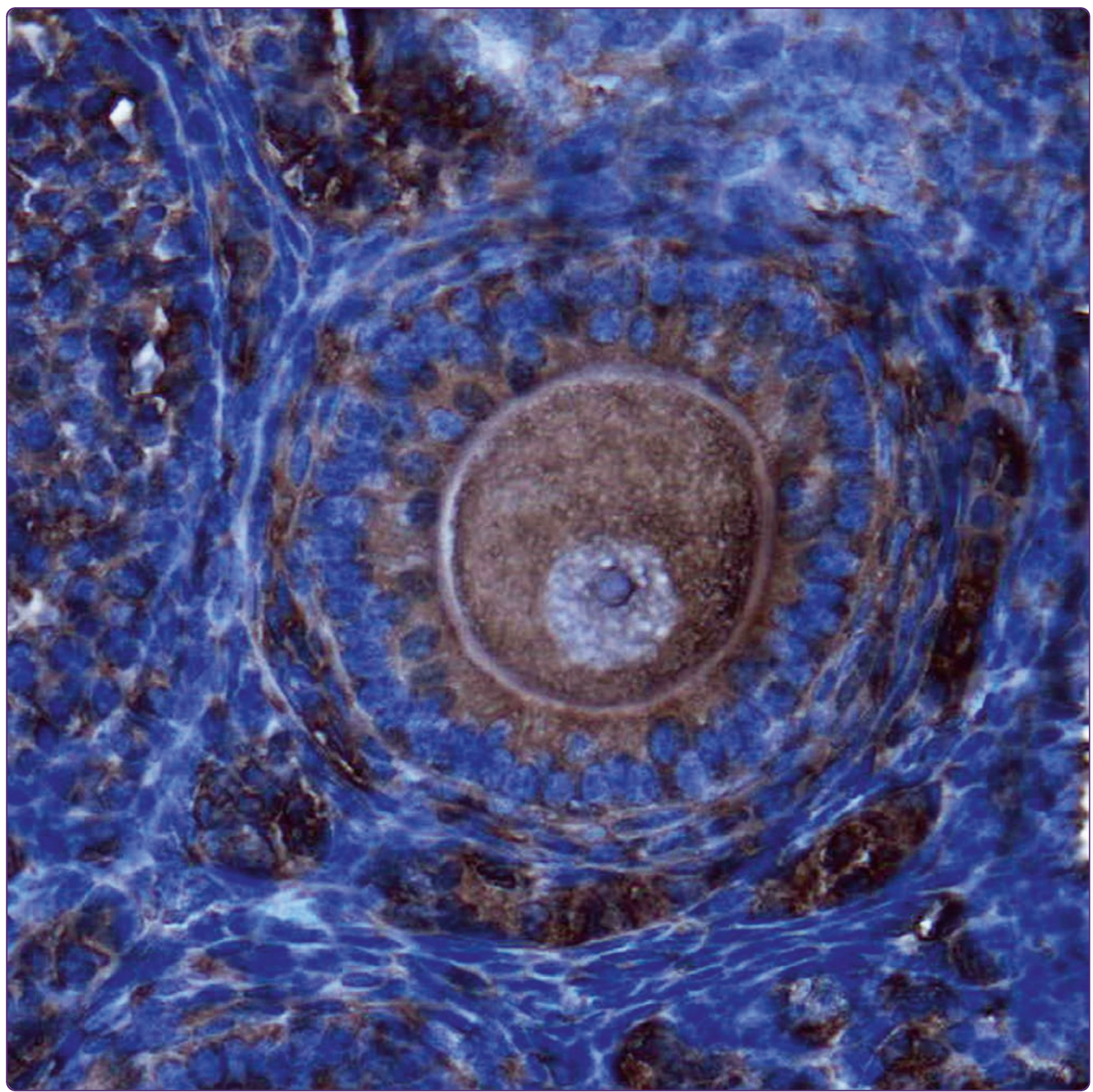

Expression of 14-3-3 protein isoforms in mouse oocytes, eggs and ovarian follicular development

De et al.

() Biomed Central 


\title{
Expression of 14-3-3 protein isoforms in mouse oocytes, eggs and ovarian follicular development
}

\author{
Santanu De, Jennifer L Marcinkiewicz, Srinivasan Vijayaraghavan and Douglas Kline*
}

\begin{abstract}
Background: The 14-3-3 (YWHA) proteins are a highly conserved, ubiquitously expressed family of proteins. Seven mammalian isoforms of 14-3-3 are known $(\beta, \gamma, \varepsilon, \zeta, \eta, \tau$ and $\sigma)$. These proteins associate with many intracellular proteins involved in a variety of cellular processes including regulation of the cell cycle, metabolism and protein trafficking. We are particularly interested in the role of 14-3-3 in meiosis in mammalian eggs and the role 14-3-3 proteins may play in ovarian function. Therefore, we examined the expression of 14-3-3 proteins in mouse oocyte and egg extracts by Western blotting after polyacrylamide gel electrophoresis, viewed fixed cells by indirect immunofluorescence, and examined mouse ovarian cells by immunohistochemical staining to study the expression of the different 14-3-3 isoforms.

Results: We have determined that all of the mammalian 14-3-3 isoforms are expressed in mouse eggs and ovarian follicular cells including oocytes. Immunofluorescence confocal microscopy of isolated oocytes and eggs confirmed the presence of all of the isoforms with characteristic differences in some of their intracellular localizations. For example, some isoforms $(\beta, \varepsilon, \gamma$, and $\zeta$ ) are expressed more prominently in peripheral cytoplasm compared to the germinal vesicles in oocytes, but are uniformly dispersed within eggs. On the other hand, 14-3-3 $\eta$ is diffusely dispersed in the oocyte, but attains a uniform punctate distribution in the egg with marked accumulation in the region of the meiotic spindle apparatus. Immunohistochemical staining detected all isoforms within ovarian follicles, with some similarities as well as notable differences in relative amounts, localizations and patterns of expression in multiple cell types at various stages of follicular development.

Conclusions: We found that mouse oocytes, eggs and follicular cells within the ovary express all seven isoforms of the 14-3-3 protein. Examination of the differential expression of these 14-3-3 isoforms in female germ cells and ovarian follicles provides the foundation for further investigating 14-3-3 isoform-specific interactions with key proteins involved in ovarian development, meiosis and oocyte maturation. This will lead to a better understanding of the individual functional roles of the 14-3-3 protein isoforms in mammalian oogenesis and female reproductive development.
\end{abstract}

\section{Background}

Members of the 14-3-3 family are key proteins in a number of intracellular events, particularly those involving phosphorylation-dependent switching. The proteins bind to a diverse set of target proteins and alter cellular function by binding to and causing conformational changes in target proteins or modifying target protein interactions with other proteins. Of particular interest, 14-3-3 appears to be central to several aspects of vertebrate development and cell cycle regulation, including

\footnotetext{
* Correspondence: dkline@kent.edu
Department of Biological Sciences, Kent State University, Kent, OH 44242,
USA

* Correspondence: dkline@kent.edu
Department of Biological Sciences, Kent State University, Kent, OH 44242,
USA USA
}

(c) 2012 De et al; licensee BioMed Central Ltd. This is an Open Access article distributed under the terms of the Creative Commons Attribution License (http://creativecommons.org/licenses/by/2.0), which permits unrestricted use, distribution, and reproduction in any medium, provided the original work is properly cited.

meiosis in amphibians [1,2]; however, the functions of 14-3-3 in mammalian reproductive organs and in gametes have not been completely elucidated. There is also interest in understanding the role of 14-3-3 proteins in the regulation of oogenesis and the cell cycle during oocyte maturation and in early development. In addition, 14-3-3 proteins, by their participation in the regulation of the cell cycle, apoptosis, and tumor suppression, are important in normal growth and development as well as in cancer [3].

The 14-3-3 proteins are a family of highly conserved, homologous proteins encoded by separate genes. The name for the protein family is tyrosine 3-monooxygenase/

\section{Biomed Central}


tryptophan 5-monooxygenase activation protein family (YWHA). The 14-3-3 name is still commonly used. There are seven mammalian isoforms of 14-3-3 encoded by seven different genes: $\beta$ (Ywhab), $\gamma$ (Ywhag), $\varepsilon$ (Ywhae), $\zeta$, (Ywhaz), $\eta$ (Ywhah), $\tau$ (Ywhaq) and $\sigma$ (Sfn) [4]. The 14-33 proteins exist as homo- or hetero-dimers [5,6]. It is known that different 14-3-3 isoforms can interact with the same ligand and so are somewhat interchangeable. Although different isoforms of 14-3-3 may bind the same protein, there are some indications that homodimers of different types or even heterodimers of 14-3-3 may have different roles in the regulation or sequestering of proteins [7-9].

The roles of 14-3-3 proteins in the ovary may parallel function in other tissues. For example, 14-3-3 $\sigma$ is expressed at lower levels in cancerous cells in a number of tissues including adenocarcinomas of the ovary $[3,10]$. However, specific descriptions of the roles of 14-3-3 proteins in the ovary are few. In female mammals, meiosis is initiated prenatally and oocytes remain arrested in an immature state at late prophase of the first meiotic division for long periods of time. This arrest is released as a result of the pre-ovulatory surge in luteinizing hormone and oocytes enter the first meiotic division cycle and arrest at metaphase II of meiosis to form the mature egg. It has been suggested that, in mammalian oocytes, 14-3-3 binds to and regulates the cell cycle control protein $\mathrm{CDC} 25 \mathrm{~B}$ phosphatase (cell division cycle 25 homolog B), as it does in amphibian oocytes, to hold the cell in prophase arrest [11]. In another case, we have shown that 14-3-3 interacts with phosphorylated PADI6, a key maternal effect protein, in mature eggs, but not with unphosphorylated PADI6 in immature oocytes [12]. While such interactions have been examined in part, more information about specific isoforms is needed. It is also clear that many more cellular processes in the ovary and in the female gametes might be regulated by 14-3-3. As a pre-requisite for understanding the role(s) of 14-3-3 in mammalian female reproductive development and oocyte maturation, we must understand which cell types express which individual isoforms. The present study explores the various isoforms of this protein and the characteristic patterns of expression in immature oocytes, mature eggs and in the various developmental stages of ovarian follicles in the adult mouse.

\section{Results and discussion}

\section{4-3-3 proteins in oocytes and eggs}

Immature, prophase I-arrested mouse oocytes and mature, metaphase II-arrested eggs appear to express all seven 14-3-3 isoforms. Three approaches were used to determine if these cells contained each of the isoforms of 14-3-3. We examined the proteins in oocyte and egg extracts by Western blotting after polyacrylamide gel electrophoresis, viewed fixed cells by indirect immunofluorescence, and examined oocytes also by immunohistochemical staining of cells within ovarian sections. All three approaches relied on a panel of antibodies that has been shown to be specific for the various 14-3-3 isoforms. Martin and his colleagues [13,14] described the generation of the panel of antibodies and used them to detect the major brain isoforms of 14-3-3. They confirmed, by several methods, the high specificity of each of these antibodies, which is due to the fact that the epitope for each antibody is mainly in the $\mathrm{N}$-acetylated amino terminus of the different peptide immunogens. The panel of 14-3-3 isoform-specific antibodies was also used to identify the isoforms of 14-3-3 proteins expressed in human dermal and epidermal layers [15] and in adrenal chromaffin cells [16].

\section{Presence and relative abundance of 14-3-3 isoforms in oocytes and eggs determined by Western blotting} Western blots of extracts from 200 oocytes or 200 eggs indicate the presence of six of the seven isoforms (Figure 1). These six isoforms of 14-3-3 were also detected in ovarian protein extracts by Western blotting. We could not detect 14-3-3 $\sigma$ by Western blotting; however, it was identified in oocytes and eggs by immunocytochemistry and in ovarian follicle cells, including oocytes, by immunohistochemical staining. The inability to

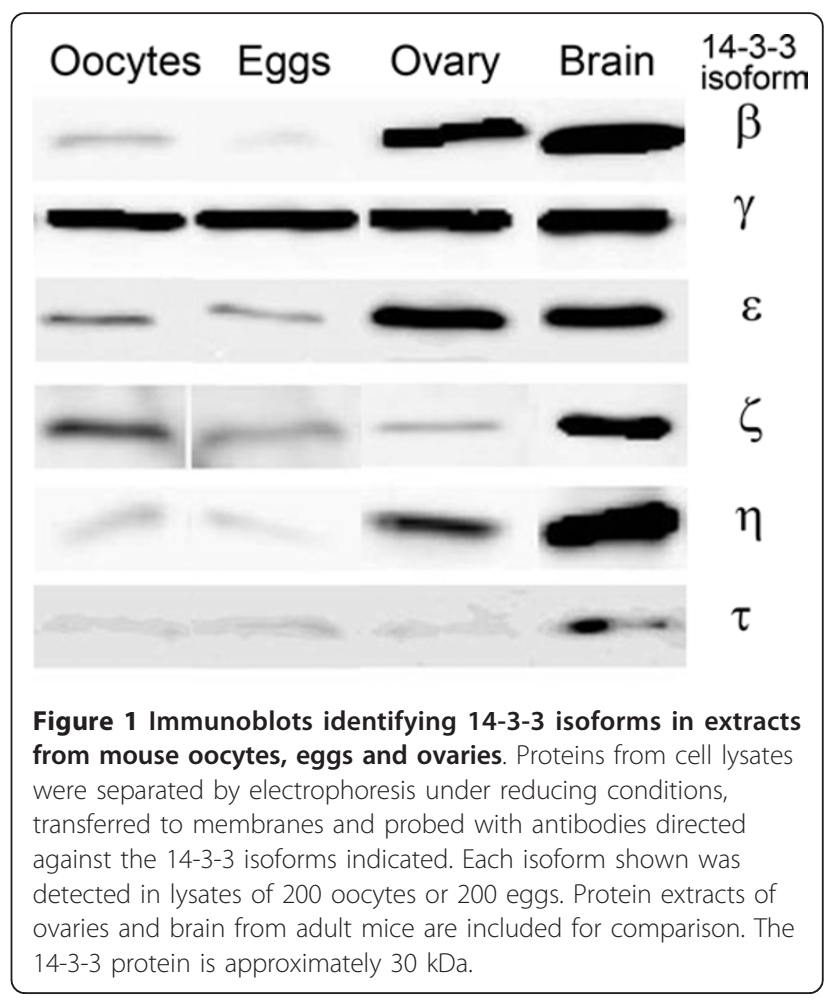


detect $14-3-3 \sigma$ in Western blots may be due to the unsuitability of this antibody in recognizing a denatured antigen in our Western blotting procedure.

We were interested to determine the relative amounts of the 14-3-3 isoforms in immature oocytes and in mature eggs. Quantitative changes in total amount of specific 14-3-3 isoforms could provide insights into the regulation of oocyte maturation or other aspects of development. Such a comparison is possible as each experiment examines proteins from the same number of oocytes or eggs (200 cells) loaded onto two lanes of gel and the proteins are simultaneously transferred to a membrane and probed with the same antibody and Western blotting reagents. The qualitative comparison of one such experiment is shown in Figure 1. We repeated this experiment two additional times and made a relative comparison for each isoform (Figure 2). The proteins $14-3-3 \beta, 14-3-3 \varepsilon, 14-3-3 \eta$, and $14-3-3 \zeta$ appear in lesser amounts in mature eggs than in immature oocytes. For example, a marked decrease in the 14-3-3 $\beta$ isoform after maturation of oocytes into eggs is observed. On the contrary, amounts of 14-3-3 $\gamma$ and 14$3-3 \tau$ were found to increase following oocyte maturation. It should be noted that, in these experiments, it is only possible to make quantitative comparisons for a single isoform and not between different isoforms as the isoform-specific antibodies may have different affinities and therefore different intensities on a Western blot.

\section{Expression of 14-3-3 isoforms in oocytes and eggs determined by immunofluorescence}

Immunofluorescence microscopy confirms the presence of all seven 14-3-3 isoforms in oocytes and eggs (Figure $3)$. Oocytes and eggs were fixed in paraformaldehyde, permeabilized with detergent and incubated with isoform-specific antibodies for 14-3-3, followed by application of a fluorescently-labeled secondary antibody and viewed by scanning confocal microscopy. The subcellular distributions of the isoforms were found to vary from one isoform to another. For example, $14-3-3 \varepsilon$ is expressed uniformly throughout the oocyte with some peripheral accumulation, and absent in the interior of the egg cytoplasm (Figure 3E-F). 14-3-3 $\tau$ is distributed uniformly in oocytes and eggs, but is particularly absent along the inner nuclear membrane of all oocytes

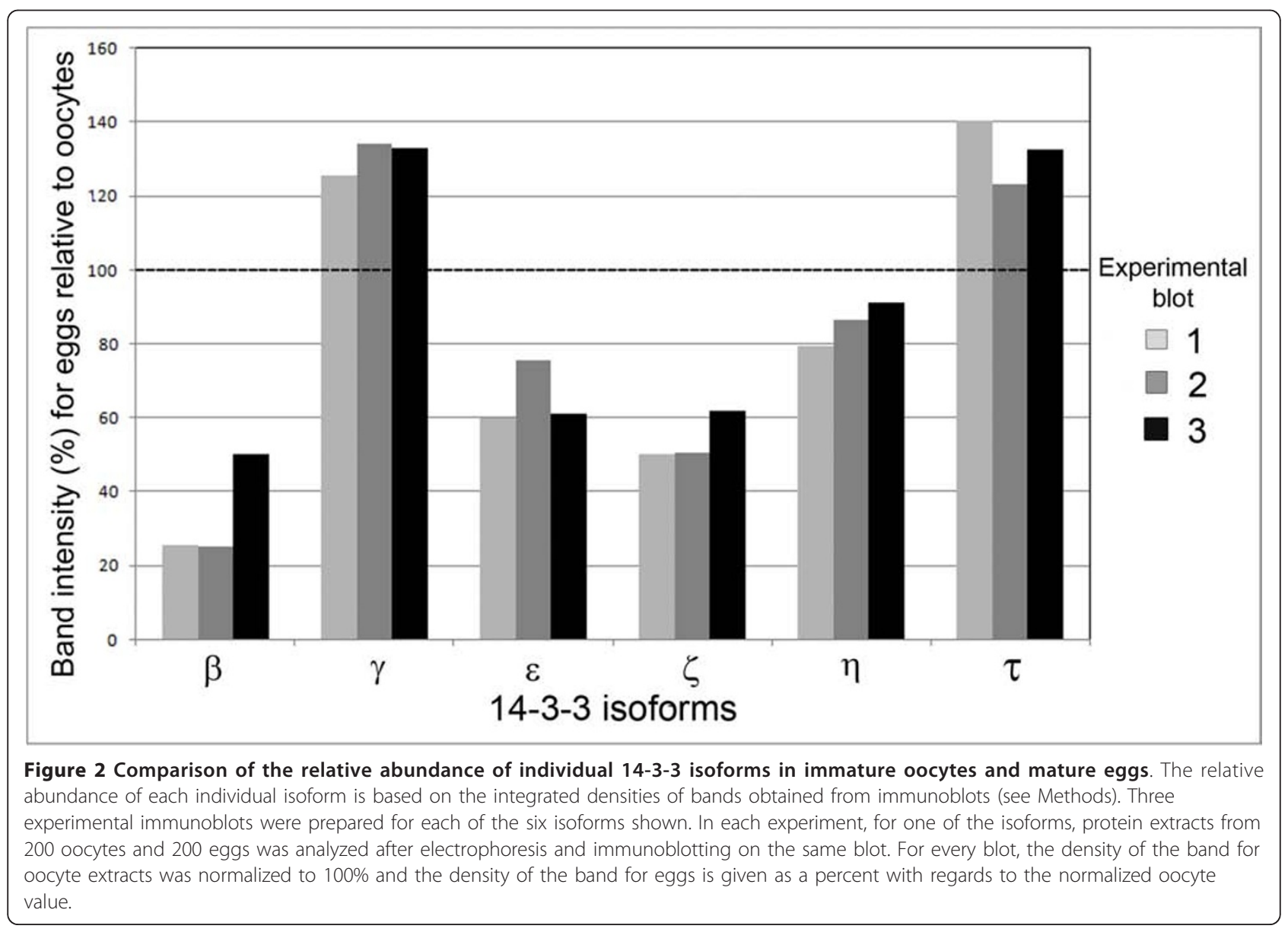




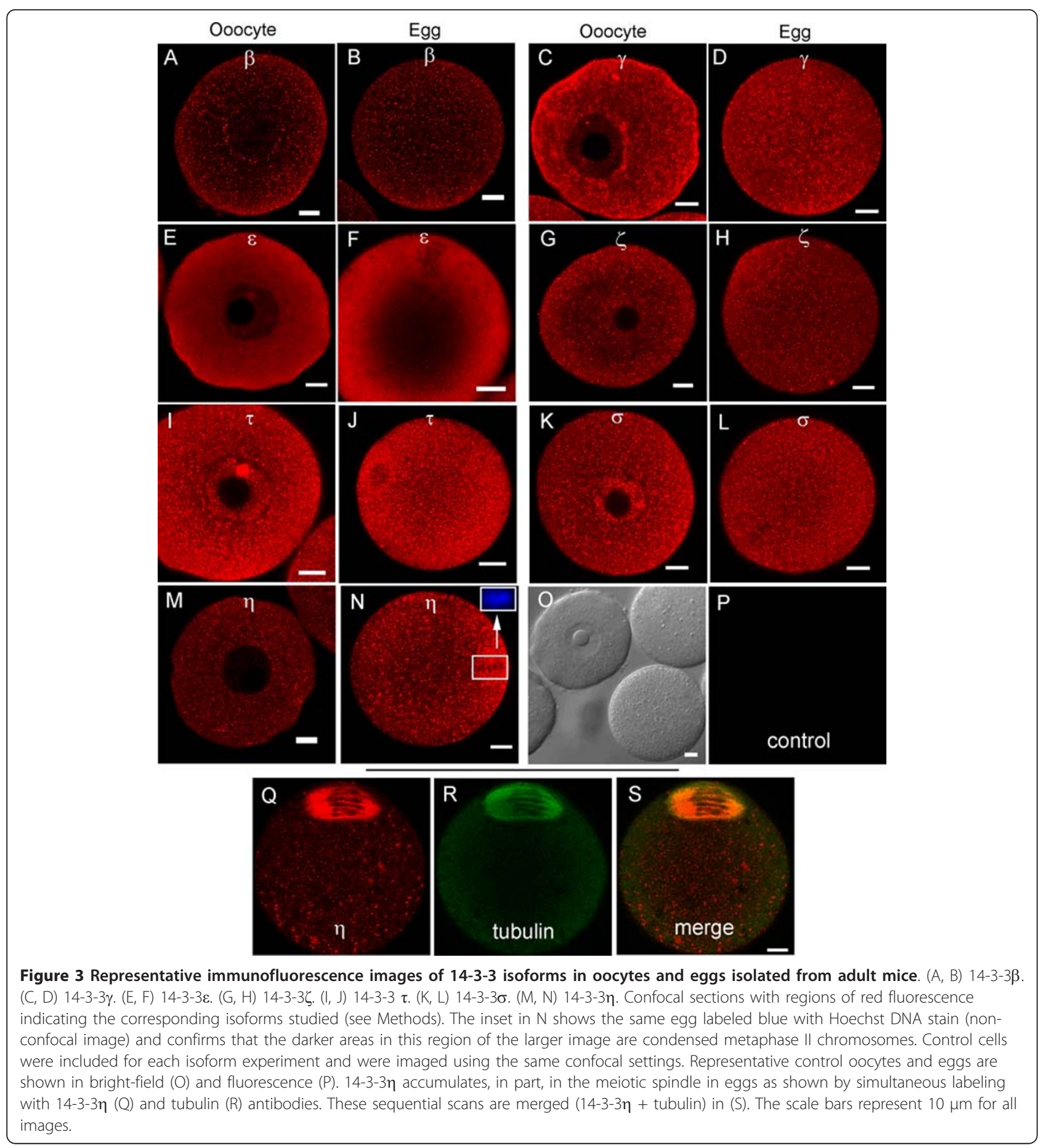

examined (Figure 3I-J). Isoforms 14-3-3 $3,14-3-3 \gamma$ and 14-3-3 3 exhibit a notable peripheral accumulation in oocytes, with a uniform distribution in eggs (Figure 3AB,3C-D and 3G-H respectively). 14-3-3 $\sigma$ is found to be expressed in higher levels in nuclei of all oocytes studied, as compared to their cytoplasm, where it is uniformly dispersed with some accumulation selectively along one half of the cell (Figure 3K); however, the 14-
3-3 $\sigma$ isoform shows a uniform distribution in eggs (Figure $3 \mathrm{~L}$ ). $14-3-3 \eta$ is diffusely dispersed in oocyte with lesser distribution in the germinal vesicle than in the cytoplasm, but attains a uniform punctuate distribution with prominent accumulation in the region of the meiotic spindle in all eggs observed (Figure 3M-N).

Control oocytes and eggs incubated in secondary antibody alone displayed little background fluorescence at 
the same laser intensities and confocal imaging settings used for each immunofluorescence experiment (Figure 3O-P). No attempt was made to compare the relative fluorescence intensity of a particular isoform in oocytes or eggs with that of a different isoform, since the antibodies detecting the isoforms were all different.

These experiments are the first to examine all of the 14-3-3 proteins in mouse oocytes and eggs. Previous work suggested that multiple isoforms could be present, for example an examination of the maternal component of the zygotic polysomal mRNA population in mouse eggs and one-cell embryos revealed an increase in maternal mRNAs for $14-3-3 \beta, 14-3-3 \gamma, 14-3-3 \zeta, 14-3-3 \eta$ and $14-3-3 \tau$. The other isoform mRNAs were not examined in this paper [17].

It has been suggested that, in mammalian oocytes, 143-3 binds to and regulates the cell cycle control protein CDC25B phosphatase [11]. There is good evidence from studies of frog oocytes that 14-3-3 protein may act to hold the oocyte in prophase I arrest by binding to and localizing phosphorylated CDC25B in the cytoplasm [18]. Following the induction of oocyte maturation, CDC25B is thought to be dephosphorylated and released from 14$3-3$, allowing it to participate in the activation of MPF which leads to germinal vesicle breakdown and the resumption of meiosis. It is not known which of the seven isoforms in the mammalian oocyte might be interacting with CDC25B; we have shown here that all are present in oocytes. The interaction of 14-3-3 with the cell cycle control protein CDC25B has been examined in mammalian somatic cells. There is strong evidence to indicate that $14-3-3 \beta, 14-3-3 \varepsilon$, and $14-3-3 \sigma$ bind to CDC25B and that 14-3-3 $\beta$ is responsible for sequestering CDC25B in the cytoplasm $[11,19]$. Future experiments will be needed to determine if the other 14-3-3 isoforms, which we have now found to be present as well in mouse oocytes, also interact with CDC25B and whether they are involved in the regulation of oocyte maturation.

Prominent localization of $14-3-3 \sigma$ in the nuclei of oocytes (Figure 3I) is consistent with the observations that 14-3-3 proteins can shuttle through the nuclear membrane, but is in contrast with some observations in somatic cells in which it was noted that $14-3-3 \sigma$ is more abundant in the cytoplasm than in the nucleus, while $14-3-3 \zeta$ is more abundant in the nucleus as compared to the cytoplasm [20].

Localization of $14-3-3 \eta$ in the meiotic spindle (Figure $3 \mathrm{~N}, \mathrm{Q}, \mathrm{R}$ and $3 \mathrm{~S}$ ) suggests a role for 14-3-3 in spindle assembly or cell cycle control. This is the first evidence for the localization of a specific 14-3-3 isoform in the metaphase II spindle of mouse eggs. It has been reported that $14-3-3 \varepsilon$ and $14-3-3 \gamma$ localize in the centrosome and mitotic spindle of some mouse somatic cells lines [21]. Additional functional studies are needed to determine if $14-3-3 \eta$ plays a role in the formation or regulation of the meiotic spindle or chromosome separation in mammalian oocytes.

\section{Expression of 14-3-3 isoforms in ovarian cells determined by immunohistochemistry}

As work on the role of 14-3-3 in ovarian development, oogenesis and cancer proceeds, it will be valuable to know which 14-3-3 isoforms are present and/or abundant in both the somatic cells and the germ cells within the ovary. We examined mouse ovarian follicular sections by immunohistochemical staining using isoformspecific antibodies and the Avidin: Biotinylated enzyme Complex $(\mathrm{ABC})$ technique. The sections contained ovarian follicles at all stages of development. The ABC method relies on the high affinity of avidin for biotin and the method is known to produce minimal background staining in the absence of primary antibody $[22,23]$. Regions stained brown indicate presence of the 14-3-3 isoforms in contrast with regions counterstained blue. Again it is not possible to determine the relative amounts of distribution of a particular isoform in cells compared to other isoforms as the antibodies are different; nevertheless for a given isoform, variations in the intensities of staining indicate differences in relative amounts of expression among different cells in follicles and surrounding tissue.

We show here by immunohistochemistry that all seven isoforms of 14-3-3 protein were detected in cells of the ovary. Follicles at various stages of development exhibit some common features of expression of the isoforms. All isoforms of 14-3-3 were detected, to varying extents, in the oocyte and cumulus cells surrounding the oocyte, mural granulosa cells, theca interna and theca externa of all follicular stages examined, as well as in cells of the corpus luteum (Figures 4, 5, 6, 7, 8, 9 and 10). In each of the follicular stages studied, all the isoforms appear to be expressed in the cytoplasm of the oocytes and to some extent in the corresponding germinal vesicles (Figures 4, 5, 6, 7, 8,9 and 10). For all isoforms, staining appeared more intense in the cytoplasm than in the nuclei of somatic cells in granulosa and theca layers as well as in cells of corpora lutea (Figures 4, 5, 6, 7, 8,9 and 10). Cells within corpora lutea were also found to have relatively higher amounts of expression of all of the isoforms as compared to surrounding interstitial cells $\mathrm{F}$ in (Figures 4, 5, 6, 7, 8,9 and 10). The isoform 14-3-3 $\tau$ appears to be expressed at lower levels in somatic cells when compared to oocytes (Figure 9AE). Atretic follicles, characterized by intensely stained pyknotic (apoptotic) and/or lytic cells, exhibit prominent accumulation of all isoforms of 14-3-3 (Figure 11A-G).

While the specific activities of 14-3-3 proteins in ovarian function are largely unknown, these proteins could 

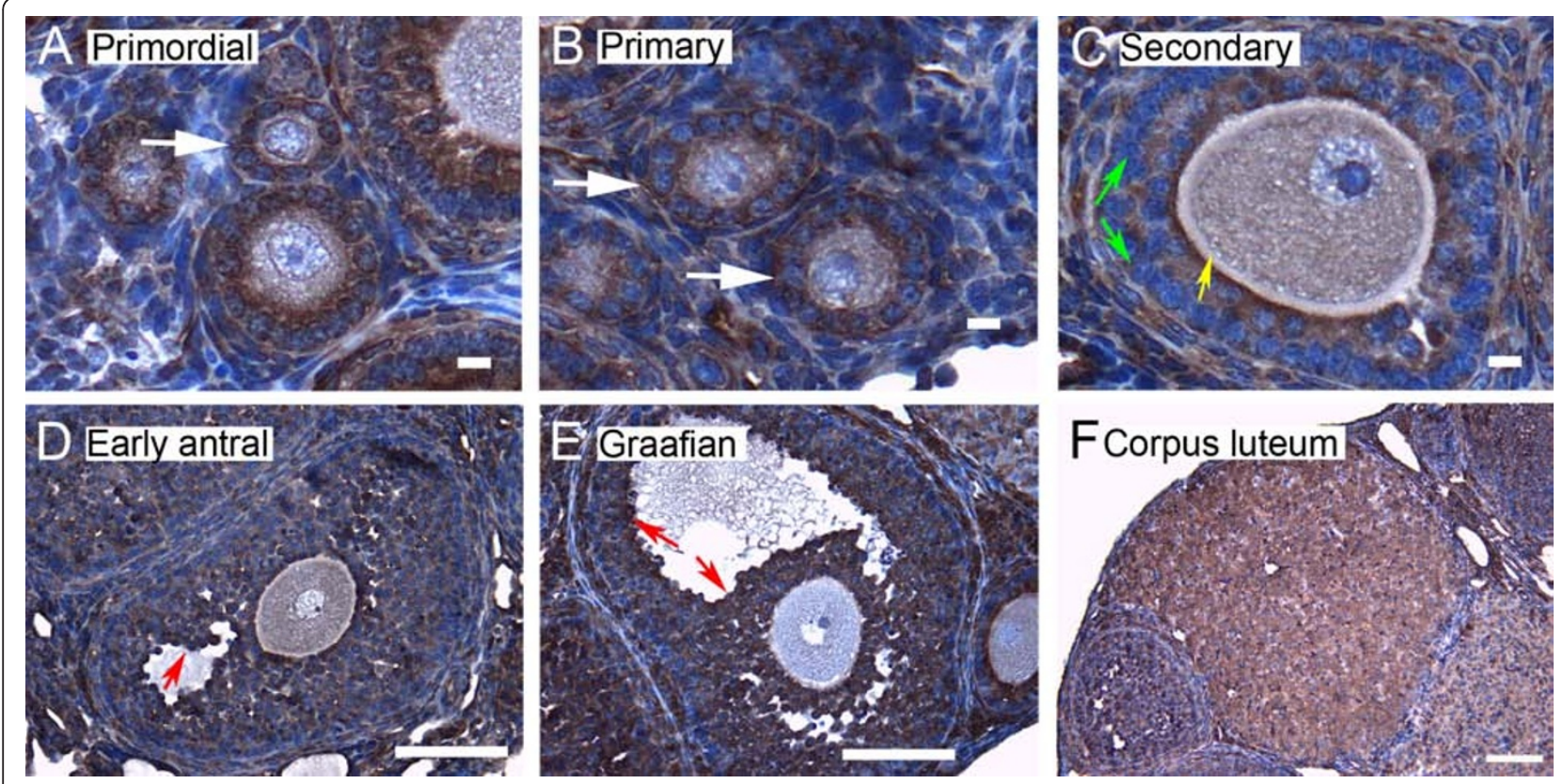

Figure 4 Representative immunohistochemistry images of 14-3-3 $\beta$ in the different stages of follicular development in ovarian sections. Brown staining represents 14-3-3 $\beta$ against regions counterstained blue with hematoxylin. (A) Primordial follicle. (B) Primary follicle. (C) Secondary follicle. (D) Early antral follicle. (E) Graafian (advanced antral) follicle. (F) Corpus luteum. White arrows indicate the primordial or primary follicles in (A and B). Note the weaker staining in mural granulosa cells in secondary follicles (C, green arrows), the more intense stain along the zona pellucida of the oocyte (C, yellow arrow), and the more intense staining in cells lining the antral cavity ( $D$ and $E$, red arrows). The scale bars represent $10 \mu \mathrm{m}(\mathrm{A}-\mathrm{C})$ or $100 \mu \mathrm{m}(\mathrm{D}-\mathrm{F})$.
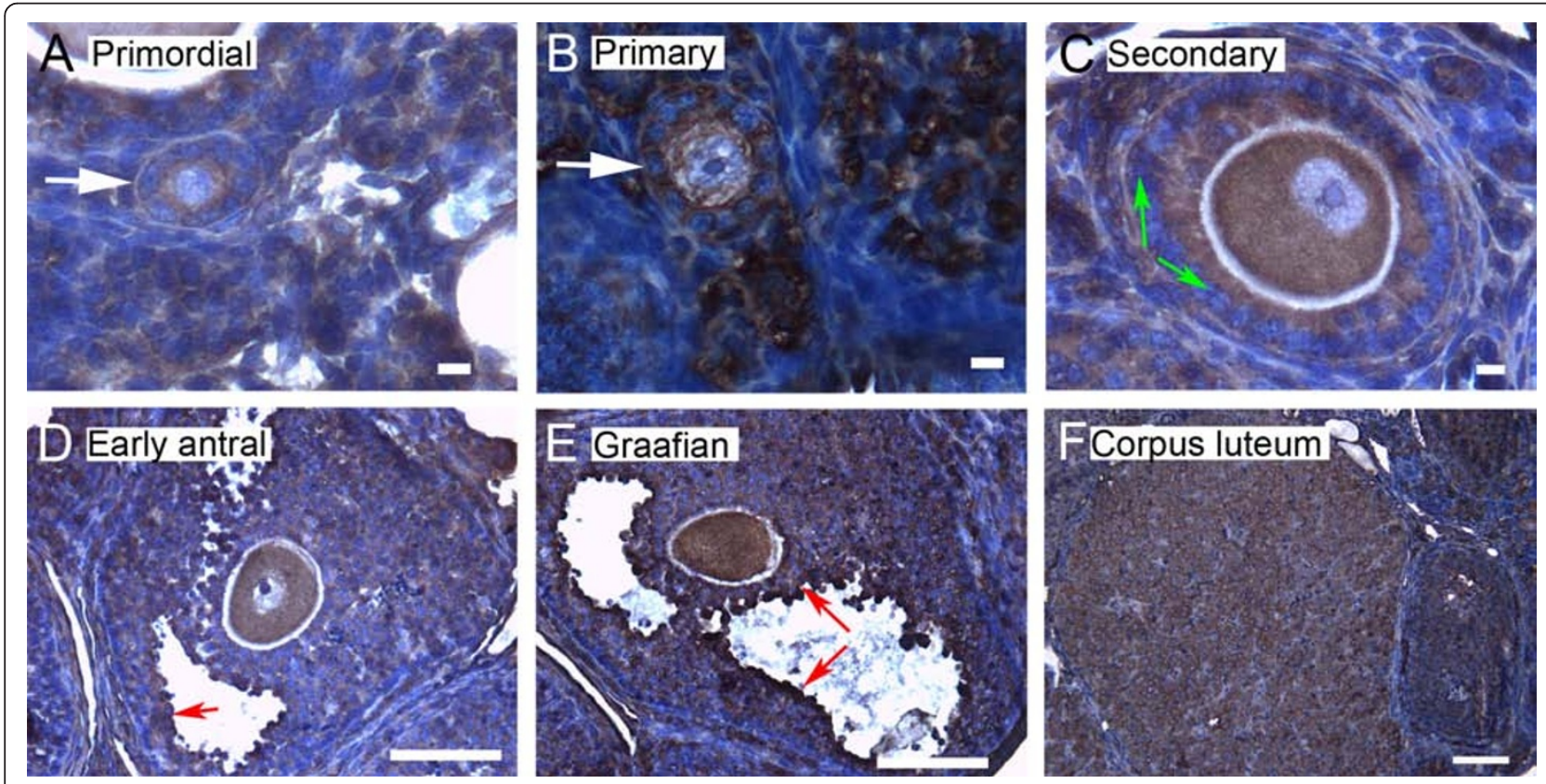

Figure 5 Representative immunohistochemistry images of 14-3-3 $\gamma$ in the different stages of follicular development in ovarian sections. (A) Primordial follicle. (B) Primary follicle. (C) Secondary follicle. (D) Early antral follicle. (E) Graafian (advanced antral) follicle. (F) Corpus luteum. White arrows indicate the primordial or primary follicles in (A and B). Note the weaker staining in mural granulosa cells in secondary follicles ( $C$, green arrows) and the more intense staining in cells lining the antral cavity ( $D$ and $E$, red arrows). The scale bars represent $10 \mu m(A-$ C) or $100 \mu \mathrm{m}(\mathrm{D}-\mathrm{F})$. 

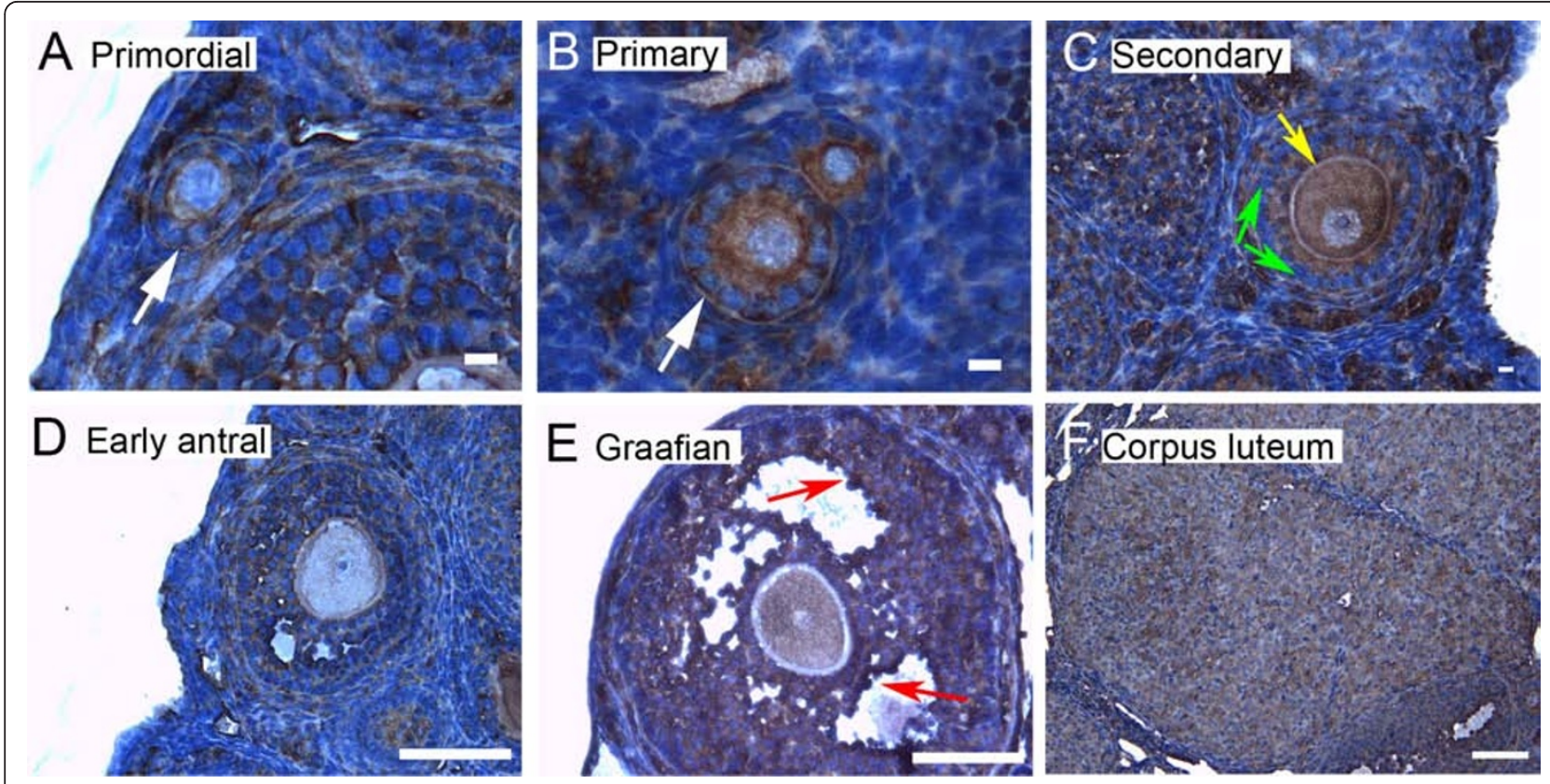

Figure 6 Representative immunohistochemistry images of 14-3-3 $\varepsilon$ in the different stages of follicular development in ovarian sections. (A) Primordial follicle. (B) Primary follicle. (C) Secondary follicle. (D) Early antral follicle. (E) Graafian (advanced antral) follicle. (F) Corpus luteum. White arrows indicate the primordial or primary follicles in (A and B). Note the weaker staining in mural granulosa cells in secondary follicles $(C$, green arrows), the more intense stain along the zona pellucida of the oocyte ( $C$, yellow arrow), and the more intense staining in cells lining the antral cavity (E, red arrows). The scale bars represent $10 \mu \mathrm{m}(\mathrm{A}-\mathrm{C})$ or $100 \mu \mathrm{m}(\mathrm{D}-\mathrm{F})$.
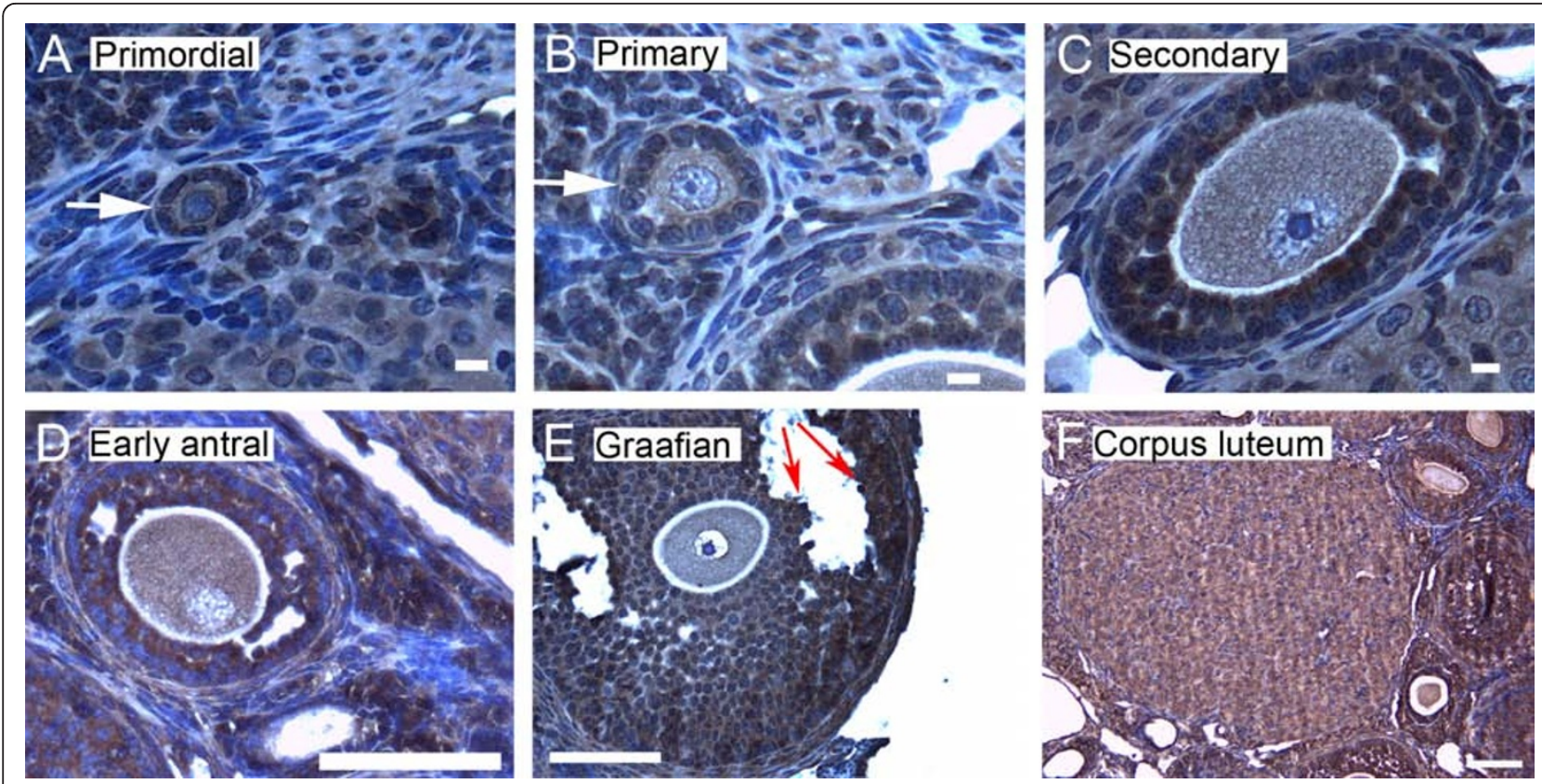

Figure 7 Representative immunohistochemistry images of 14-3-3 $\zeta$ in the different stages of follicular development in ovarian sections. (A) Primordial follicle. (B) Primary follicle. (C) Secondary follicle. (D) Early antral follicle. (E) Graafian (advanced antral) follicle. (F) Corpus luteum. White arrows indicate the primordial or primary follicles in (A and B). Note the more intense staining in cells lining the antral cavity ( $E_{\text {, }}$ red arrows). The scale bars represent $10 \mu \mathrm{m}(\mathrm{A}-\mathrm{C})$ or $100 \mu \mathrm{m}(\mathrm{D}-\mathrm{F})$. 

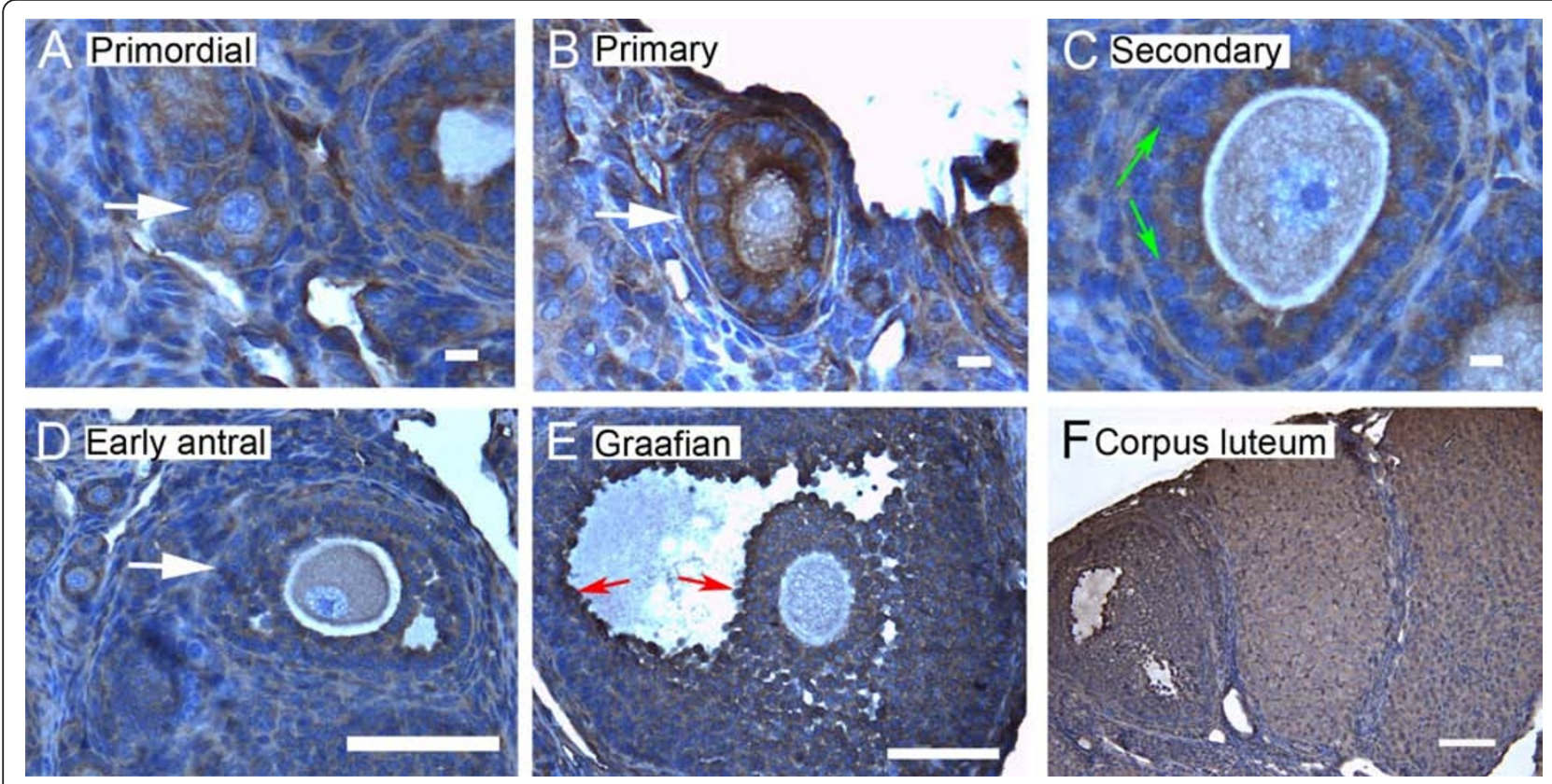

Figure 8 Representative immunohistochemistry images of 14-3-3 $\eta$ in the different stages of follicular development in ovarian sections. (A) Primordial follicle. (B) Primary follicle. (C) Secondary follicle. (D) Early antral follicle. (E) Graafian (advanced antral) follicle. (F) Corpus luteum. White arrows indicate the primordial or primary follicles in (A and B). Note the weaker staining in mural granulosa cells in secondary follicles ( $C$, green arrows) and the more intense staining in cells lining the antral cavity ( $E$, red arrows). The scale bars represent $10 \mu \mathrm{m}(\mathrm{A}-\mathrm{C})$ or $100 \mu \mathrm{m}(\mathrm{D}-\mathrm{F})$

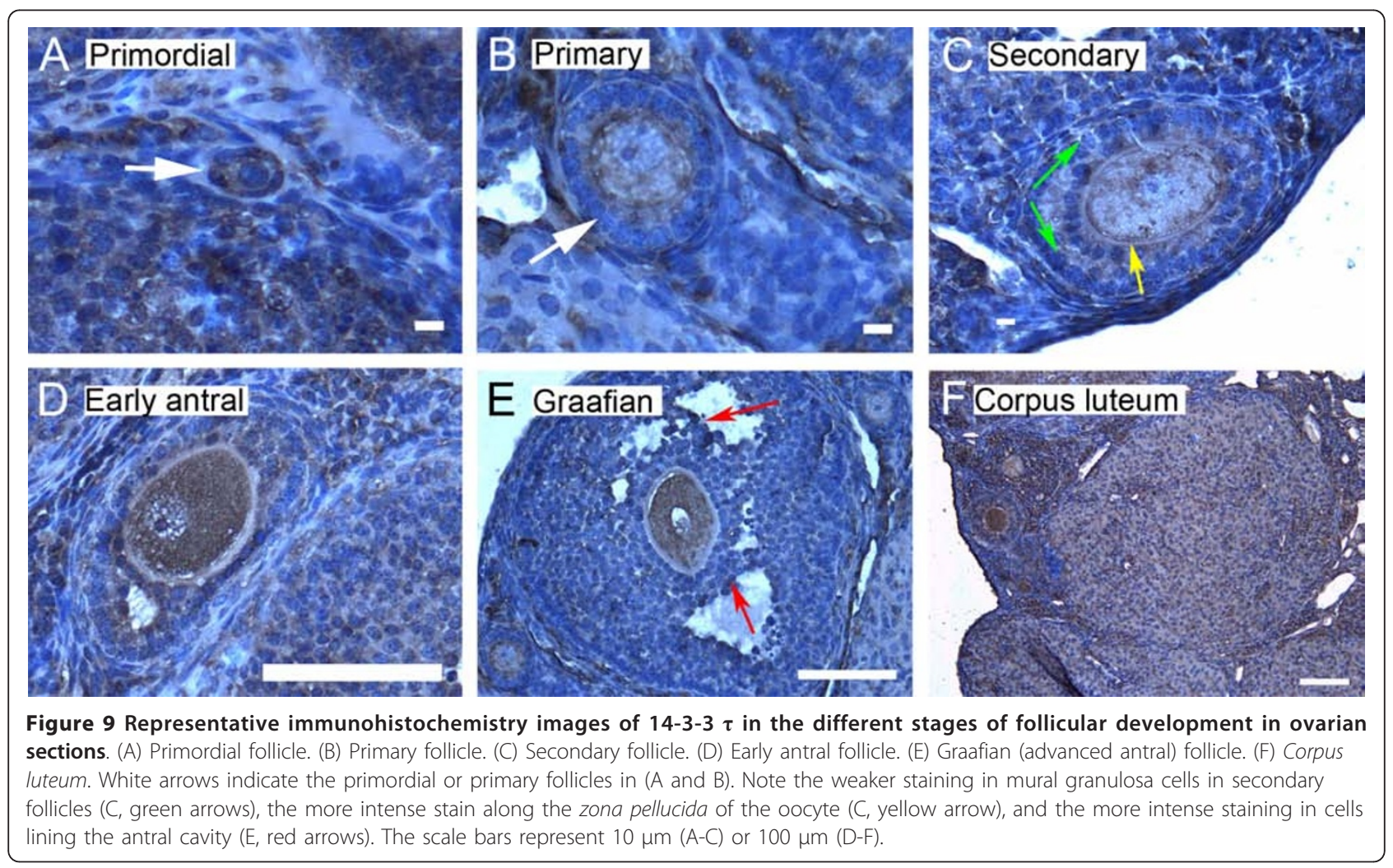



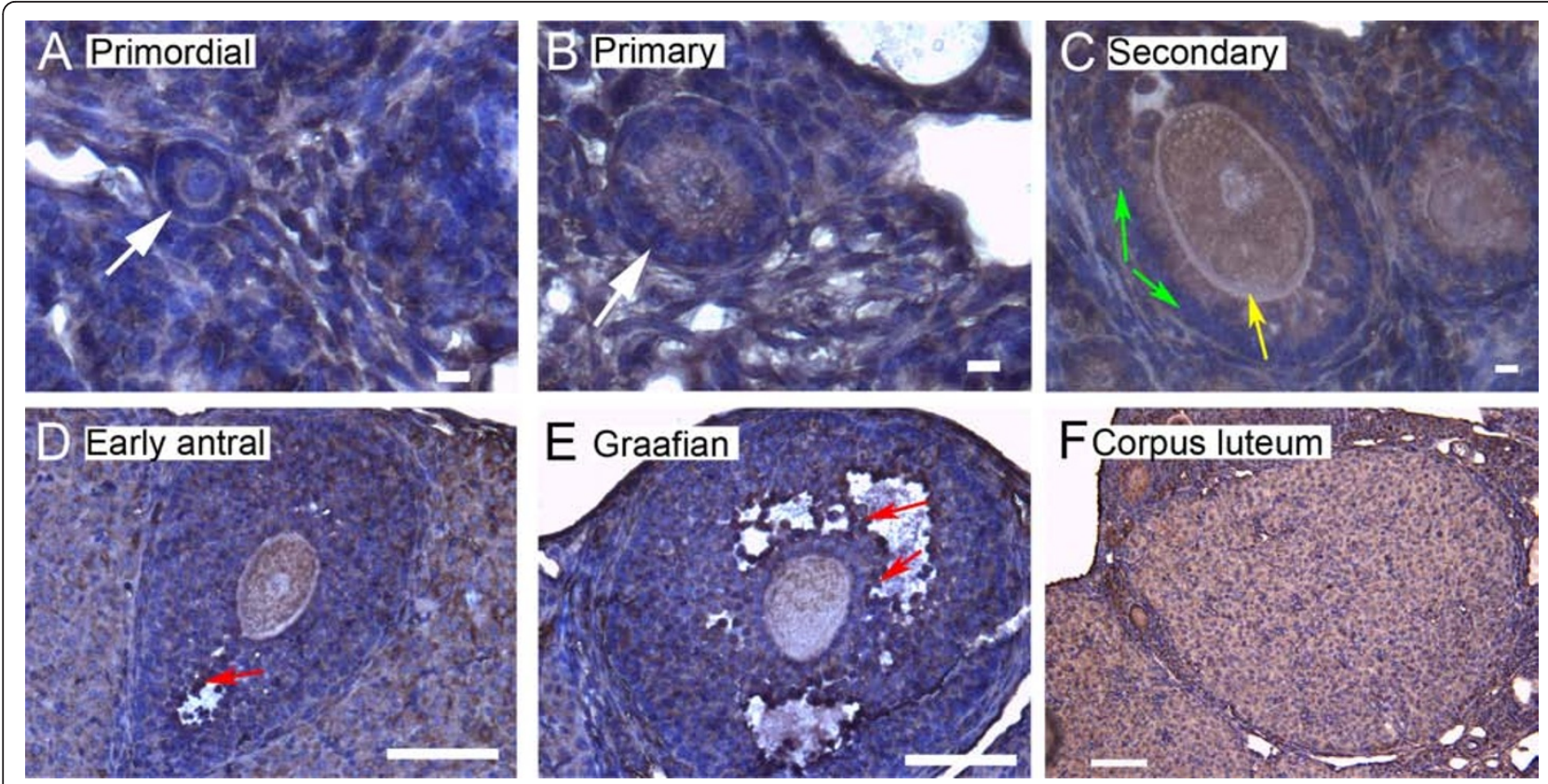

Figure 10 Representative immunohistochemistry images of 14-3-3 $\sigma$ in the different stages of follicular development in ovarian sections. (A) Primordial follicle. (B) Primary follicle. (C) Secondary follicle. (D) Early antral follicle. (E) Graafian (advanced antral) follicle. (F) Corpus luteum. White arrows indicate the primordial or primary follicles in (A and B). Note the weaker staining in mural granulosa cells in secondary follicles ( $C$, green arrows), the more intense stain along the zona pellucida of the oocyte ( $C$, yellow arrow), and the more intense staining in cells lining the antral cavity ( $D$ and $E$, red arrows). The scale bars represent $10 \mu \mathrm{m}(\mathrm{A}-\mathrm{C})$ or $100 \mu \mathrm{m}(\mathrm{D}-\mathrm{F})$.

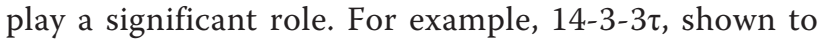
be present in human granulosa cells, has been shown to bind to the human follitropin (follicle stimulating hormone, FSH) receptor suggesting a role for 14-3-3 proteins in follitropin signaling in granulosa cells $[24,25]$. The reason for intense 14-3-3 staining in apoptotic cells is not known. 14-3-3 is generally associated with antiapoptotic functions [26]. 14-3-3 proteins appear to be involved in several ways in promoting cell survival, for example 14-3-3 has been found to enhance the activity of proteins with proliferative or survival roles, such as members of the Raf family, while antagonizing the activity of proteins that promote cell death $[3,27]$. There is some suggestion that $14-3-3 \sigma$ is associated with the survival of granulosa cells and inhibition of 14-3-3 interaction with target proteins, without regard to isoform, promotes apoptosis in these cells $[28,29]$.

Several characteristic differences in expression of 143-3 protein isoforms in different stages of follicular development were observed by immunohistochemical staining. Detection of 14-3-3 $\beta, 14-3-3 \gamma, 14-3-3 \varepsilon, 14-3-$ $3 \tau$ and $14-3-3 \sigma$ in zonae pellucidae of oocytes by immunohistochemical staining indicates secretion of some 14-3-3 proteins into the zonae and perivitelline space (Table 1; C in Figures 4, 6, 9 and 10). To examine this by another method, we isolated zona-intact oocytes and viewed them by immunofluorescence.
Such immunocytochemical staining detected the same isoforms along the membranes of the isolated oocytes and within or along the zonae pellucidae of oocytes (Figure 112B, D, F, L and N), indicating secretion of those 14-3-3 isoforms by the oocyte or associated follicle cells. Control oocytes processed for fluorescence microscopy without the addition of primary antibody showed no fluorescence above background (Figure 12O-P).

The function, if any, of extracellular 14-3-3 surrounding the oocyte is not yet known. We do not believe this is an artifact of fixation since the appearance of the extracellular 14-3-3 was found by two different methods and the absence of staining for some isoforms argues against nonspecific artifacts. We did not find extracellular 14-3-3 proteins associated with mature, ovulated eggs, which also suggests that this is not an artifact (data not shown). While the 14-3-3 proteins are generally known as intracellular proteins, some 14-3-3 proteins are known to be secreted by somatic cells; for example, it has been known for some time that 14-3-3 proteins are found in the cerebrospinal fluid [30] where they may serve as markers for Creutzfeldt-Jakob disease. Keratinocytes secrete 14-3-3 $\sigma$ which induces expression of matrix metalloproteinase 1 (MMP1 or collagenase) in fibroblasts [31]. Three isoforms, 14-3-3 $\sigma, 14-3-3 \gamma$ and

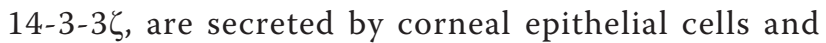



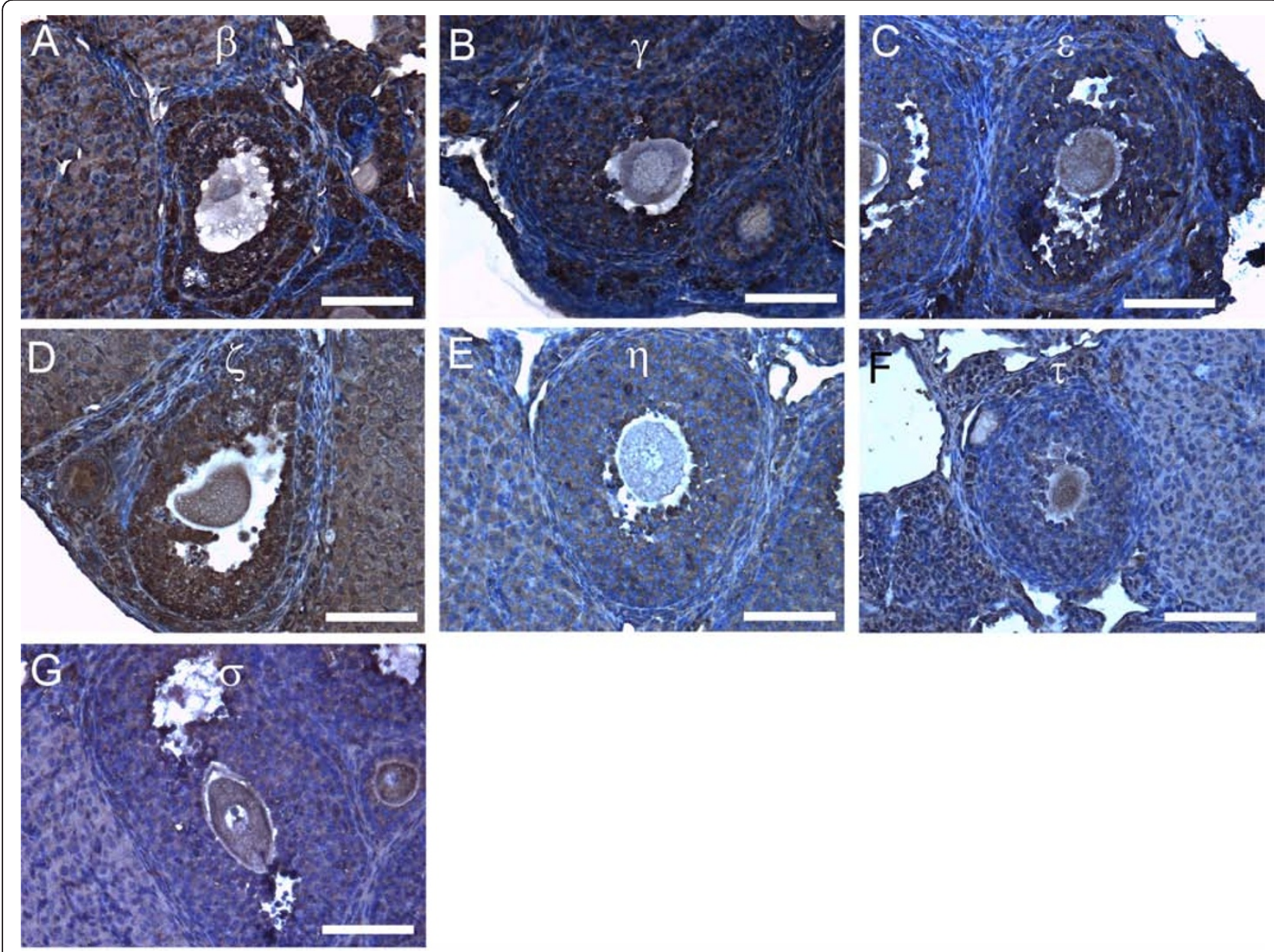

Figure 11 Representative immunohistochemistry images of 14-3-3 protein isoforms in atretic follicles of adult mouse ovaries. (A) 14-3-

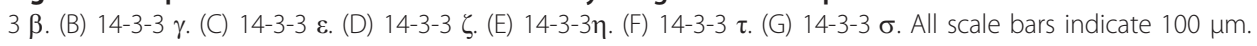

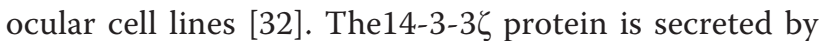
certain tumor associated inflammatory cells [33].

Another notable difference in the distribution of 14-33 isoforms in ovarian folliculogenesis is prominent lack

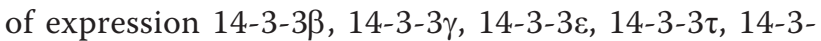
$3 \eta$ and $14-3-3 \sigma$ in the peripheral mural granulosa cells, as compared to other cells of secondary, early antral and/or Graafian follicles (Table 1; C in Figures 4, 5 and 6 and 8,9 and 10). At early antral stages, intense stain-

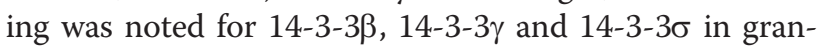
ulosa cells surrounding the antrum (Table 1; D in Figures 1, 2 and 10). At the Graafian stage, all isoforms appear to accumulate in these cells (Table 1; E in Figures $4,5,6,7,8,9$ and 10).

\section{Conclusions}

Seven isoforms of the protein 14-3-3 are expressed in the female mouse germ cells and in cells of mouse ovarian follicles at various stages of development. There are characteristic differences in the relative amount and distribution of 14-3-3 proteins in oocytes and eggs. Pro-

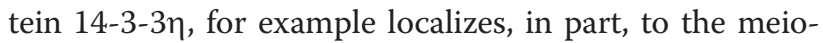
tic spindle in eggs. A number of isoforms appear to be extracellular and associated with the zona pellucida in ovarian oocytes. The distribution of some 14-3-3 isoforms within cells of the ovary differs, for example with peripheral mural granulosa cells expressing some isoforms and not others. All 14-3-3 isoforms appear to be present in relatively greater amounts in cells lining the antral cavity of Graafian follicles and in granulosa cells of atretic follicles. These results will enable further research investigating 14-3-3 interactions with other key proteins involved in ovarian development and gamete function.

\section{Methods}

Collection of Oocytes and Eggs and Preparation of Ovarian Tissue Extracts

All mice used in the present experiments were housed and used at Kent State University under an approved 
Table 1 Characteristic differences in expression of 14-3-3 protein isoforms in the different stages of follicular development as observed by immunohistochemical staining of adult mouse ovarian sections

\begin{tabular}{|c|c|c|c|c|}
\hline \multirow[t]{2}{*}{ Feature } & \multirow[t]{2}{*}{ Isoform } & \multicolumn{3}{|c|}{ Stage of Ovarian Follicle } \\
\hline & & Secondary & Early Antral & Graafian \\
\hline $\begin{array}{l}\text { Expression } \\
\text { in zonae pellucidae } \\
\text { around } \\
\text { oocytes }\end{array}$ & 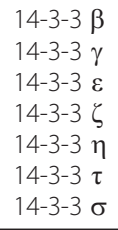 & $\begin{array}{l}++ \\
+ \\
++ \\
+ \\
- \\
++ \\
++\end{array}$ & $\begin{array}{l}++ \\
+ \\
++ \\
+ \\
- \\
++ \\
++\end{array}$ & $\begin{array}{l}++ \\
+ \\
++ \\
- \\
- \\
++ \\
++\end{array}$ \\
\hline $\begin{array}{l}\text { Prominent } \\
\text { lack of expression } \\
\text { in peripheral mural granulosa } \\
\text { cells }\end{array}$ & $\begin{array}{l}14-3-3 \beta \\
14-3-3 \gamma \\
14-3-3 \varepsilon \\
14-3-3 \zeta \\
14-3-3 \eta \\
14-3-3 \tau \\
14-3-3 \sigma \\
\end{array}$ & $\begin{array}{l}\text { Yes } \\
\text { Yes } \\
\text { Yes } \\
\text { No } \\
\text { Yes } \\
\text { Yes } \\
\text { Yes } \\
\end{array}$ & $\begin{array}{l}\text { Yes } \\
\text { No } \\
\text { No } \\
\text { No } \\
\text { No } \\
\text { No } \\
\text { No } \\
\end{array}$ & $\begin{array}{l}\text { Yes } \\
\text { Yes } \\
\text { Yes } \\
\text { No } \\
\text { No } \\
\text { Yes } \\
\text { Yes } \\
\end{array}$ \\
\hline $\begin{array}{l}\text { Marked accumulation } \\
\text { in granulosa cells surrounding the antrum }\end{array}$ & 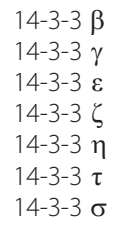 & & $\begin{array}{l}\text { Yes } \\
\text { Yes } \\
\text { No } \\
\text { No } \\
\text { No } \\
\text { No } \\
\text { Yes }\end{array}$ & $\begin{array}{l}\text { Yes } \\
\text { Yes } \\
\text { Yes } \\
\text { Yes } \\
\text { Yes } \\
\text { Yes } \\
\text { Yes }\end{array}$ \\
\hline
\end{tabular}

'++' = Considerable expression; ' + ' = Some expression;

'-' = Non-detectable expression; 'Yes' = Presence of the feature; 'No' = Feature not detectable

Institutional Animal Care and Use Committee protocol following the National Research Council's publication Guide for the Care and Use of Laboratory Animals. Oocytes and eggs were collected as previously described [12]. CD1 mice (2.5 months old) were injected with 7.5 IU eCG and, 44-48 h later, the ovaries were removed and repeatedly punctured with a 26 -gauge needle to rupture follicles. Cumulus cell-enclosed oocytes were isolated and the cumulus cells were removed by repeated pipetting though a small-bore pipette. Fullygrown oocytes with intact nuclei (germinal vesicles) were cultured in MEM containing $0.1 \mathrm{mg} / \mathrm{ml}$ dibutyryl cAMP to prevent spontaneous oocyte maturation. Mature, metaphase II-arrested eggs were obtained from mice 13-14 h following superovulation by injection of 7.5 IU hCG which was preceded by a priming injection of 7.5 IU eCG injection $48 \mathrm{~h}$ earlier. The cumulus cells were removed with $0.3 \mathrm{mg} / \mathrm{ml}$ hyaluronidase. Zonae pellucidae from oocytes and eggs thus collected were removed by a brief treatment in acid Tyrode's solution (0.14 M NaCl, $3 \mathrm{mM} \mathrm{KCl}, 1.6 \mathrm{mM} \mathrm{CaCl} 2.2 \mathrm{H}_{2} \mathrm{O}, 0.5$ $\mathrm{mM} \mathrm{MgCl} 2.6 \mathrm{H}_{2} \mathrm{O}, 5.5 \mathrm{mM}$ glucose, and $0.1 \%$ PVA, $\mathrm{pH}$ 2.5). Cells were rinsed in MEM and prepared for use in Western blot or immunocytochemistry as described below.

\section{SDS-PAGE, Western Blotting and Protein Analysis}

14-3-3 isoforms were identified through multiple Western blots (using standard Western blotting procedures), each testing for one of the seven isoforms in protein extracts. Oocytes and eggs were rinsed in MEM, counted, and transferred to Tris-buffered saline (TBS; $25 \mathrm{mM}$ Tris- $\mathrm{HCl}[\mathrm{pH} 7.5]$ and $150 \mathrm{mM} \mathrm{NaCl}$ ) containing $0.1 \%$ PVA. Cells were removed from the TBS, lysing buffer was added, and the cell lysates were quick-frozen in ethanol/dry ice and stored at $-70^{\circ} \mathrm{C}$ until use. The lysis buffer contained $10 \mathrm{mM}$ Tris- $\mathrm{HCl}$ [pH 7.2], $1 \mathrm{mM}$ EDTA, $1 \mathrm{mM}$ EGTA, 0.1\% (v/v) b-mercaptoethanol, 1\% (v/v) Triton X-100, protease inhibitors (1 mM PMSF, $0.1 \mathrm{mM}$ TPCK, $10 \mu \mathrm{M}$ leupeptin, $1 \mu \mathrm{M}$ pepstatin $\mathrm{A}$, and $75 \mathrm{nM}$ aprotinin), and phosphatase inhibitors (1 $\mathrm{mM}$ $\mathrm{Na}_{3} \mathrm{VO}_{4}, 100 \mathrm{nM}$ calyculin A, $10 \mathrm{mM}$ beta-glycerophosphate, and $5 \mathrm{mM}$ sodium pyrophosphate).

Proteins from the lysates of 200 oocytes or 200 eggs were separated by SDS-PAGE using a $4 \%$ stacking, $12 \%$ resolving polyacrylamide gel and electrophoretically transferred to Immobilon-P PVDF membrane (Millipore Corp.). The membranes were incubated in blocking buffer (5\% milk in TBS, $0.1 \%$ Tween-20) and then with primary antibodies overnight at $4{ }^{\circ} \mathrm{C}$, washed and incubated with secondary antibody and imaged by chemiluminescence with an enhanced chemiluminescence kit according to the manufacturer's instructions (GE Healthcare Life Sciences) using the Fujifilm LAS-3000 luminescent image analyzer. Protein extracts of ovaries from adult mice were included for comparison, loading identical amounts of protein extract for all isoform immunoblots. Brain extract, loaded with the same amount of protein extract for each isoform, was used as a positive control for all isoforms of 14-3-3 except 14-3-3 $\sigma$ for which skin 

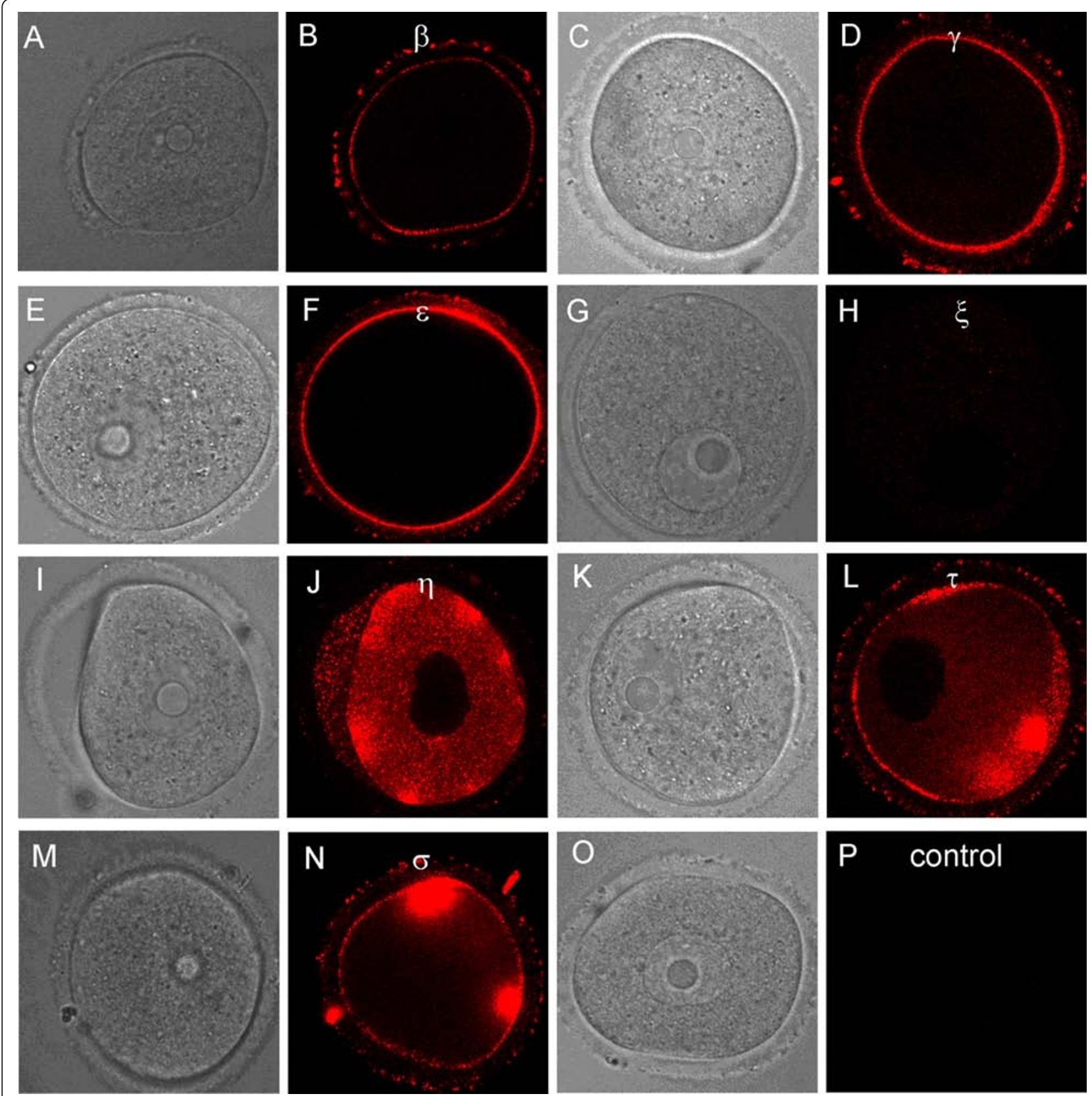

Figure 12 Representative immunocytochemistry images of 14-3-3 protein isoforms along and in the zonae pellucidae of cumulus-free oocytes isolated from ovaries of adult mice. The zona-intact cells were fixed in paraformaldehyde but not treated with detergent (see Methods). Paired images of an oocyte (left image is brightfield and right is immunofluorescence) indicate staining along the zona and/or the cell

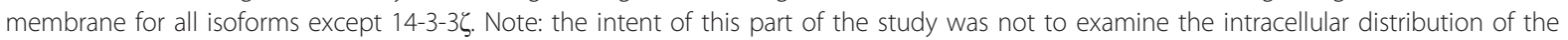
isoforms (see Figure 3 for those experiments) since the cells were not permeabilized to permit complete antibody penetration; however, cells may be partially permeabilized by fixation accounting for the detection of intracellular proteins in some cells. (A,B) 14-3-3 $\beta$. (C,D) 14-3-3 $\gamma$. (E,F)

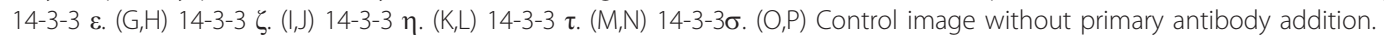

extract was used as positive control. This is because all isoforms of 14-3-3 have been indentified in brain except

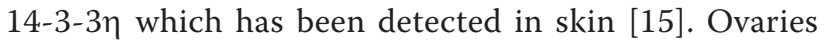
from unprimed adult mice (2.5 months old), brain and skin tissues were homogenized in a buffer containing
(10 mM Tris pH 7.0, 1 mM EDTA, 1 mM EGTA, 0.16\% benzamidine hydrochloride, $14 \mathrm{mM}$ beta-mercaptoethanol, $1 \mathrm{mM}$ PMSF and 0.1 mM TPCK) pH 7.2, using a mechanical homogenizer. The homogenized cell lysates were then centrifuged at $16,000 \mu \mathrm{g}$ for $30 \mathrm{~min}$ and the 
supernatants containing the total soluble protein extracts were used for SDS-PAGE and Western blotting.

We used the commercial rabbit anti-14-3-3 isoform panel (PAN017) from AbD Serotec, for Western blotting as well as immunocytochemical and immunohistochemical staining (see below) of the different 14-3-3 isoforms in mouse ovaries, oocytes and eggs. The immunogens, against which the antibodies were raised, were synthetic peptides corresponding to acetylated $\mathrm{N}$-terminal sequences of sheep 14-3-3 proteins. They are raised against synthetic peptides corresponding to the following acetylated $\mathrm{N}$-terminal sequences of sheep 14-3-3 isoforms: 14-3-3 3 , TMDKSELVC; 14-3-3 $\gamma$, VDREQLVQKAC; $14-3-3 \varepsilon$, MDDREDLVYQAKC; 14-3-

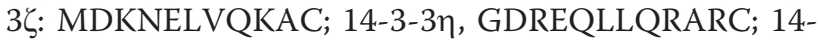
3-3 $\tau$, MEKTELIQKAC; 14-3-3 $\sigma$, MERASLIQKAC.

Two additional antibodies to $14-3-3 \beta$ and $14-3-3 \zeta$ were also used to confirm the presence of these isoforms (rabbit anti-14-3-3 $\beta$, sc-628 and rabbit anti-14-3$3 \zeta$ sc-1019, Santa Cruz Biotechnology). All antibodies were used at a dilution of 1:1,000 in blocking buffer $(5 \%$ milk in $1 \mathrm{X}$ TBS, $0.1 \%$ Tween-20). The secondary antibody for all experiments was HRP-conjugated goat antirabbit (Genscript; $1 \mathrm{mg} / \mathrm{ml}$ stock) used at a dilution of $1: 2,000$ in the blocking buffer.

The relative abundance of each 14-3-3 isoform in oocytes and eggs was determined in a semi-quantitative manner. Proteins from 200 oocytes and 200 eggs were separated by electrophoresis on the same gel, transferred to membrane at the same time and immunoblotted together under the same conditions using one of the six 14-3-3 antibodies. This procedure was repeated two additional times with the same antibody. There will be inherent differences in the intensities of bands for each immunoblot processed, but for a given blot the intensity of the egg band can be compared to the intensity of the oocyte band. To summarize the three experiments for each of the six isoforms, the band intensities for oocyte and egg lanes in a given blot were analyzed using NIH image and compared to each other. The intensity of the oocyte band was normalized to $100 \%$ for each blot and the egg intensity (reflecting the relative protein amount) was then expressed as a percentage of the oocyte intensity for each of the three blots analyzed for each isoform. Note that no comparison should be drawn for the band intensities among the isoforms since the antibodies detecting the isoforms were different from each other, with possible differences in their affinities.

\section{Immunocytochemistry of oocytes and eggs}

Oocytes and eggs were fixed in freshly prepared 3.7\% paraformaldehyde for 30-60 min, washed in PBS-PVA (PBS containing 1\% PVA), permeabilized with 1\% Triton $\mathrm{X}-100$ to promote antibody penetration, washed in PBS-
PVA, then treated with blocking buffer (5\% normal goat serum in PBS-PVA), and incubated overnight with each of the primary antibodies for 14-3-3 isoforms (rabbit anti-14-3-3 isoform panel PAN017, AbD Serotec; diluted $1: 200$ in $1 \%$ goat serum blocking buffer). Following washing, the cells were incubated with Cy3-conjugated goat anti-rabbit secondary antibody (Jackson ImmunoResearch Laboratories) diluted 1:200 in blocking buffer for several hours, washed again and transferred to an anti-fade solution (SlowFade; Invitrogen). All cells were imaged with the Olympus Fluoview FV500 confocal microscopy system using a $60 \times$ oil immersion lens and various confocal zooms; the scale bars on the images indicate the final magnification. Images were captured and examined at multiple confocal planes. The representative images shown here are primarily images at the plane of the optical equator. For each isoform experiment, 5-7 oocytes and 5-7 eggs were examined at the same time under the same staining and imaging conditions. The experiment was repeated twice for each isoform.

In oocytes, the nucleus is readily discernible in fluorescence images or the corresponding brightfield images. In eggs, the location of the condensed metaphase II chromosomes can sometimes be determined by a bulge at one pole of the egg or by the absence of fluorescence causing an outline of the unlabeled chromosomes. In an additional experiment using the 14-3-3 $\eta$ antibody, condensed meiotic chromosomes in eggs were identified by staining with the DNA-staining Hoechst dye $(0.001 \mathrm{mg} /$ $\mathrm{ml}$ ) and imaged with conventional epifluorescence microscopy (Figure 3N, inset). In several experiments, eggs were simultaneously incubated in both the 14-3-3 $\eta$ isoform antibody and an antibody to alpha-tubulin to identify the meiotic spindle microtubules (rat anti-alpha tubulin; sc-69970; $200 \mu \mathrm{g} / \mathrm{ml}$ diluted 1:200 in 1\% blocking buffer; Santa Cruz Biotechnology). The secondary antibody was FITC-conjugated goat anti-rat from (Jackson Laboratories) (diluted 1:200 in blocking buffer). In all cases, control oocytes and eggs were incubated in secondary antibody alone and imaged using the same confocal settings as used for experimental, antibodylabeled cells. Background fluorescence was minimal.

An additional set of immunofluorescence experiments was performed to examine the presence of extracellular 14-3-3 isoforms associated with isolated oocytes. The immunofluorescence method was used as described above, but with several changes. In this case, the zonae were not removed before fixation in $3.7 \%$ paraformaldehyde and the cells were not treated Triton X-100 to permeabilize the cell membranes following fixation. All other staining procedures were the same. We wanted to look at the possibility of secreted proteins in oocytes. This experiment was not intended to examine the 
intracellular distribution of isoforms (see above methods and Figure 3 for that experiment); however, we have known for many years that mouse oocytes and eggs sometimes are partially permeabilized on fixation alone (no detergent added). Therefore some staining within the oocytes may occur, but is not be a complete representation since the permeability of cells may vary from cell to cell and is not uniform within a cell.

\section{Immunohistochemistry of tissue sections}

Ovaries, brain and skin tissues were collected from unprimed adult mice (2.5 months old) and fixed in $4 \%$ paraformaldehyde in PBS overnight. They were then dehydrated through a graded series of ethanol followed by two changes of CitriSolv and embedded in paraffin. Multiple microtome tissue sections of $6 \mu \mathrm{m}$ thickness were transferred to slides pre-coated with poly-Llysine. Following removal of paraffin and rehydration, antigens were recovered by boiling the sections for 1 min, three times in Antigen Retrieval Citra solution (\#HK086-5K, Biogenex) with intermittent cooling. Tissue sections were then cooled at room temperature for $30 \mathrm{~min}$ and then washed in deionised water for $5 \mathrm{~min}$. Endogenous peroxidase was blocked by incubation of tissue sections in $0.3 \%$ hydrogen peroxide for $30 \mathrm{~min}$. Tissues were then incubated for $20 \mathrm{~min}$ in PBS blocking buffer or $0.15 \%$ normal goat serum (VectaStain Elite ABC Kit, \#PK-6101, Vector Laboratories). Tissues sections were incubated overnight at $4{ }^{\circ} \mathrm{C}$ in a humidified chamber with each of the different primary antibodies (14-3-3 isoform panel PAN017, AbD Serotec, see above) diluted in blocking buffer at dilutions recommended by the manufacturer and a prior study

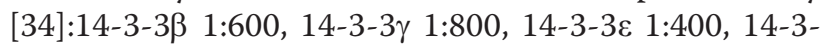

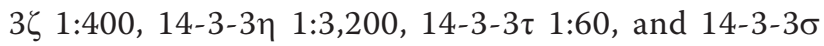
$1: 100$. The same dilutions were used for positive control sections. The rabbit serum used in matching negative control sections, were immunostained at a dilution identical to that used in corresponding sample sections for the isoforms.

Following antibody incubation, slides containing tissue sections were washed in buffer (PBS, pH 7.5) for $5 \mathrm{~min}$, incubated for $30 \mathrm{~min}$ in biotinylated secondary antibody (VectaStain Elite ABC Kit, Vector Laboratories) diluted in blocking buffer and washed again in buffer for $5 \mathrm{~min}$. This was followed by incubation of the tissues for 30 min in VectaStain Elite ABC Reagent (prepared according to the manufacturer's instructions; Vector Laboratories). DAB substrate was prepared using Vector Laboratories DAB peroxidase substrate Kit (SK-4100) according to instructions specified in kit. Tissues were treated with DAB substrate for 3-4 min until development of optimum brown color, rinsed with tap water and counter-stained with Hematoxylin.
The ABC-immunostaining method produces minimal background staining. To examine the background staining, two sets of negative controls were used. One set of tissue sections was processed without the addition of primary antibodies. Since the primary antibodies were rabbit polyconlonals, the other control set utilized tissue sections incubated in normal rabbit serum (Jackson ImmunoResearch) prior to incubation with the secondary antibodies. In both cases, control sections did not show brown staining, confirming specific localization by this method. Brain tissue sections were used as positive control for all isoforms of 14-3-3 except $14-3-3 \sigma$ for which skin tissue was used as positive control (see Figure 13). This is because all isoforms of 14-3-3 have been identified in brain with the exception of $14-3-3 \sigma$ [13]. Skin sections were used as positive control for $14-3-3 \sigma$ since $14-3-3 \sigma$ is known to be found in epidermis [15] (see Figure 13). For each isoform, dilutions of primary antibodies or rabbit serum for positive and negative controls were kept identical. Each 14-3-3 isoform was studied individually in a set of 3 separate stained ovarian tissue sections, along with simultaneous staining of appropriate positive and negative controls. In addition the studies were repeated on sections obtained from the ovary of a different unprimed adult mouse of the same age. The characteristic features for all 14-3-3 isoforms, as identified by immunohistochemical staining, were examined and tabulated (Table 1) independently by three individuals with agreement on the observations.
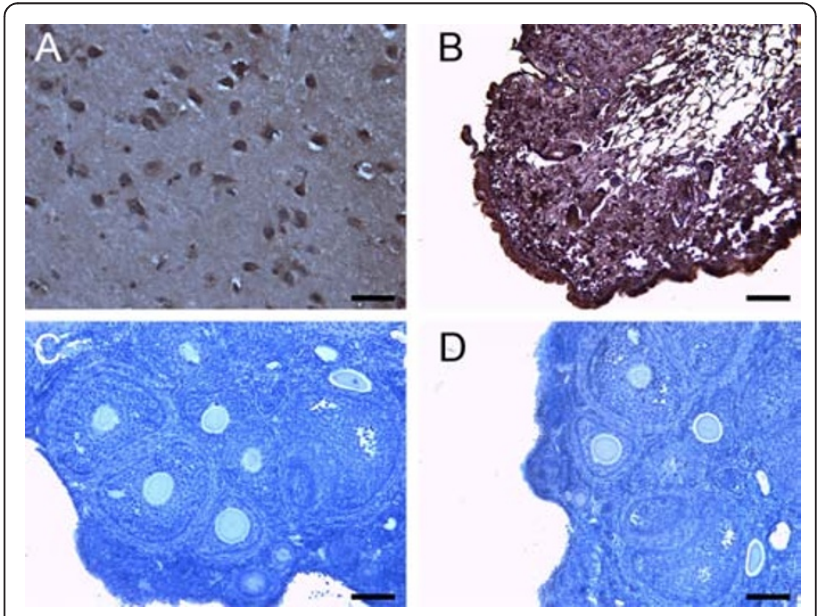

Figure 13 Representative control immunohistochemistry images for the different 14-3-3 protein isoforms in tissue sections. (A) Example of a positive control brain section obtained for all 14-3-3 isoforms except for 14-3-3 $\sigma$. (B) Skin positive control for 14-3-3 $\sigma$. (C) Example of a negative control section with no primary antibody obtained for all isoforms. (D) Example of a negative control with rabbit serum in place of primary antibody obtained for all isoforms. All scale bars indicate $100 \mu \mathrm{m}$. 


\section{Abbreviations}

ABC: Avidin-biotin complex; CDC25B: Cell division cycle 25 homolog B; Cy3: Cyanin3; DAB: 3,3' Diaminobenzidine; eCG: Equine chorionic gonadotropin; FITC: Fluorescein isothiocyanate; hCG: Human chorionic gonadotropin; HRP: Horse radish peroxidase; MEM: Minimal essential medium; PADI6: Peptidyl arginine deiminase 6; PMSF: Phenylmethylsulfonyl fluoride; PVDF: Polyvinylidene fluoride; TBS: Tris buffered saline; TPCK: Tosyl phenylalanyl chloromethyl ketone; Tris-HCl: Tris-hydrochloride; YWHA: Tyrosine 3monooxygenase/tryptophan 5-monooxygenase activation protein.

\section{Acknowledgements}

We thank Dr. Michael Model, Department of Biological Sciences, Kent State University Imaging Facility for assistance and Benjamin Villarreal, Adam Schulte and Nicholas Misener for helping with the immunofluorescence experiments. This work was supported by National Institutes of Grants HD061869 to DK and HD038520 to SV.

\section{Authors' contributions}

SD, JLM and DK conducted all practical work. All authors reviewed the data and combined to draft the manuscript. All authors read and approved the final version of the manuscript.

\section{Competing interests}

The authors declare that they have no competing interests.

Received: 6 October 2011 Accepted: 23 January 2012

Published: 23 January 2012

\section{References}

1. Lau JMC, Wu CL, Muslin AJ: Differential role of 14-3-3 family members in Xenopu development. Dev Dyn 2006, 235(7):1761-1776.

2. Margolis S, Perry J, Weitzel D, Freel C, Yoshida M, Haystead T, Kornbluth S: A role for PP1 in the Cdc2/Cyclin B-mediated positive feedback activation of Cdc25. Mol Biol Cell 2006, 17(4):1779-1789.

3. Morrison DK: The 14-3-3 proteins: integrators of diverse signaling cues that impact cell fate and cancer development. Trends Cell Biol 2009, 19(1):16-23.

4. Aitken A: 14-3-3 proteins: a historic overview. Semin Cancer Biol 2006, 16(3):162-172

5. Jones DH, Ley S, Aitken A: Isoforms of 14-3-3-protein can form homodimers and heterodimers in-vivo and in-vitro - implications for function as adapter proteins. FEBS Lett 1995, 368(1):55-58.

6. Chaudhri M, Scarabel M, Aitken A: Mammalian and yeast 14-3-3 isoforms form distinct patterns of dimers in vivo. Biochem Biophys Res Commun 2003, 300(3):679-685.

7. Aitken A: Functional specificity in 14-3-3 isoform interactions through dimer formation and phosphorylation. Chromosome location of mammalian isoforms and variants. Plant Mol Biol 2002, 50(6):993-1010.

8. Benzinger A, Muster N, Koch HB, Yates JR, Hermeking H: Targeted proteomic analysis of 14-3-3 sigma, a p53 effector commonly silenced in cancer. Mol Cell Proteomics 2005, 4(6):785-795.

9. Mackintosh C: Dynamic interactions between 14-3-3 proteins and phosphoproteins regulate diverse cellular processes. Biochem J 2004, 381:329-342.

10. Mhawech-Fauceglia P, Herrmann FR, Andrews C, South S, Beck A, Lele S, Odunsi K: 14-3-3 sigma expression and prognostic value in patients with epithelial ovarian carcinoma: a high throughput tissue microarray analysis. Ejso 2009, 35(7):763-767

11. Pirino G, Wescott MP, Donovan PJ: Protein kinase a regulates resumption of meiosis by phosphorylation of Cdc25B in mammalian oocytes. Cell Cycle 2009, 8(4):665-670.

12. Snow AJ, Puri P, Acker-Palmer A, Bouwmeester T, Vijayaraghavan S, Kline D: Phosphorylation-dependent interaction of tyrosine 3-monooxygenase/ tryptophan 5-monooxygenase activation protein (YWHA) with PAD16 following ocyte maturation in mice. Biol Reprod 2008, 79(2):337-347.

13. Martin H, Rostas J, Patel Y, Aitken A: Subcellular-localization of 14-3-3isoforms in rat-brain using specific antibodies. J Neurochem 1994, 63(6):2259-2265.

14. Martin H, Patel Y, Jones D, Howell S, Robinson K, Aitken A: Antibodies against the major brain isoforms of 14-3-3-protein-an antibody specific for the N-acetylated amino-terminus of a protein. FEBS Lett 1993, 331(3):296-303.

15. Kilani RT, Medina A, Aitken A, Jalili RB, Carr M, Ghahary A: Identification of different isoforms of 14-3-3 protein family in human dermal and epidermal layers. Mol Cell Biochem 2008, 314(1-2):161-169.

16. Roth D, Morgan A, Martin H, Jones D, Martens G, Aitken A, Burgoyne R: Characterization of 14-3-3 proteins in adrenal chromaffin cells and demonstration of isoform-specific phospholipid binding. Biochem J 1994, 301:305-310.

17. Potireddy $S$, Vassena R, Patel BG, Latham KE: Analysis of polysomal mRNA populations of mouse oocytes and zygotes: dynamic changes in maternal mRNA utilization and function. Dev Biol 2006, 298(1):155-166.

18. Margolis SS, Walsh S, Weiser DC, Yoshida M, Shenolikar S, Kornbluth S: PP1 control of M phase entry exerted through 14-3-3-regulated Cdc25 dephosphorylation. EMBO J 2003, 22(21):5734-5745.

19. Uchida S, Kuma A, Ohtsubo M, Shimura M, Hirata M, Nakagama H, Matsunaga T, Ishizaka Y, Yamashita K: Binding of 14-3-3 beta but not 14-33 sigma controls the cytoplasmic localization of CDC25B: binding site preferences of 14-3-3 subtypes and the subcellular localization of CDC25B. J Cell Sci 2004, 117(14):3011-3020.

20. van Hemert M, Niemantsverdriet M, Schmidt T, Backendorf C, Spaink H: Isoform-specific differences in rapid nucleocytoplasmic shuttling cause distinct subcellular distributions of $1433 \sigma$ and 1433 3. J Cell Sci 2004, 117(8):1411-1420.

21. Pietromonaco S, Seluja G, Aitken A, Elias L: Association of 14-3-3 proteins with centrosomes. Blood Cells Mol Dis 1996, 22(19):225-237.

22. Hsu SM, Raine L, Fanger H: A comparative-study of the peroxidaseantiperoxidase method and an avidin-biotin complex method for studying polypeptide hormones with radioimmunoassay antibodies. Am J Clin Pathol 1981, 75(5):734-738.

23. Hsu SM, Raine L, Fanger H: Use of avidin-biotin-peroxidase complex (abc) in immunoperoxidase techniques-a comparison between $\mathrm{Abc}$ and unlabeled antibody (Pap) procedures. J Histochem Cytochem 1981, 29(4):577-580.

24. Cohen B, Nechamen C, Dias J: Human follitropin receptor (FSHR) interacts with the adapter protein 14-3-3 tau. Mol Cell Endocrinol 2004, 220(1-2):1-7.

25. Dias JA, Mahale SD, Nechamen CA, Davydenko O, Thomas RM, UlloaAguirre A: Emerging roles for the FSH receptor adapter protein APPL1 and overlap of a putative 14-3-3 tau interaction domain with a canonical G-protein interaction site. Mol Cell Endocrinol 2010, 329(12):17-25.

26. Rosenquist M: 14-3-3 Proteins in Apoptosis. Braz J Med Biol Res 2003, 36(4):403-408.

27. Porter G, Khuri F, Fu H: Dynamic 14-3-3/client protein interactions integrate survival and apoptotic pathways. Semin Cancer Biol 2006, 16(3):193-202.

28. Peluso JJ, Pappalardo A: Progesterone regulates granulosa cell viability through a protein kinase G-dependent mechanism that may involve 143-3 sigma. Biol Reprod 2004, 71(6):1870-1878.

29. Peluso JJ, Liu X, Romak J: Progesterone maintains basal intracellular adenosine triphosphate levels and viability of spontaneously immortalized granulosa cells by promoting an interaction between 14-33 sigma and ATP synthase beta/precursor through a protein kinase Gdependent mechanism. Endocrinology 2007, 148(5):2037-2044.

30. Wiltfang J, Otto M, Baxter H, Bodemer M, Steinacker P, Bahn E, Zerr I, Kornhuber J, Kretzschmar H, Poser S, Ruther E, Aitken A: Isoform pattern of 14-3-3 proteins in the cerebrospinal fluid of patients with CreutzfeldtJakob disease. J Neurochem 1999, 73(6):2485-2490.

31. Ghaffari A, Li Y, Karami A, Ghaffari M, Tredget E, Ghahary A: Fibroblast extracellular matrix gene expression in response to keratinocytereleasable stratifin. J Cell Biochem 2006, 98(2):383-393.

32. Shankardas J, Senchyna M, Dimitrijevich SD: Presence and distribution of 14-3-3 proteins in human ocular surface tissues. Mol Vis 2008, 14:2604-2615.

33. Kobayashi R, Deavers M, Patenia R, Rice-Stitt T, Halbe J, Gallardo S, Freedman RS: 14-3-3 zeta protein secreted by tumor associated monocytes/macrophages from ascites of epithelial ovarian cancer patients. Cancer Immunol Immunother 2009, 58(2):247-258.

34. Baxter H, Liu W, Forster J, Aitken A, Fraser J: Immunolocalisation of 14-3-3 isoforms in normal and scrapie-infected murine brain. Neuroscience 2002, 109(1):5-14. 
- Convenient online submission

- Thorough peer review

- No space constraints or color figure charges

- Immediate publication on acceptance

- Inclusion in PubMed, CAS, Scopus and Google Scholar

- Research which is freely available for redistribution 